the occurrence of scheelite in pegmatites at a contact of granite and quartzite, with chalcopyrite and molybdenite. Even stranger is the presence of scheelite in quartz veins, with chalcopyrite, molybdenite, and pyrite in a gangue of quartz and calcite. Wolfram appears to be entirely absent, which suggests that there must have been a strange scarcity of iron in the rocks concerned. All this provides an interesting example of a curious type of pneumatolysis, and the detailed descriptions given in the Bulletins seem to show clearly that the granite or its emanations were of a very special type. It is just such special types that are difficult to explain on current theories of granitization, while they are of first-class interest in the theory of ore-deposits.

\title{
CORRESPONDENCE
}

\section{AN ESTIMATE OF THE AGE OF THE EARTH}

DEAR SIR,-In a highly interesting paper Holmes ${ }^{1}$ gives the remarkably consistent results of age calculations based on the relative abundances of the isotopes in twenty-five samples of lead, as determined by Nier and his co-workers. The outcome is roughly $3 \times 10^{9}$ years. We must congratulate him on having again advanced our knowledge of geological ages by a marked achievement. But I believe it should be emphasized that what has been ascertained is not, as Holmes states, the "age of the earth", but the " age of the materials forming the earth". Our conceptions of the birth of the solar system and the earth are vague, but in current opinion the zero time that Holmes has determined would not apply to the earth but to some earlier event, that for convenience might be called the birth of the Milky Way. The subsequent formation of the earth as a separate entity came later and there is no reason for supposing that the clock Holmes has read for us, was set to zero again by that revolution. Hence, the earth is younger than 3,000 million years. The difference need be only a small amount, but it may also amount to a large fraction of the estimated age.

I hope this remark will serve to clarify a minor point in an otherwise lucid and epoch-making contribution from the great time keeper among geologists.

PH. H. Kuenen.

Geological Institute,

Groningen, NeTHERLands.

${ }^{1}$ A. Holmes. An Estimate of the Age of the Earth. Nature, vol. 157, p. $680,1946$. 